\title{
Upgrade to Cardiac Device with Additional Pacing Capabilities
}

National Cancer Institute

\section{Source}

National Cancer Institute. Upgrade to Cardiac Device with Additional Pacing Capabilities. NCI Thesaurus. Code C100030.

A device with additional pacing capabilities is replacing the current device. (ACC) 